\title{
Mariléia Sell
}

Universidade do Vale do Rio dos Sinos

\section{"Minha mãe ficou amarga": expectativas de performances de maternidade negociadas na fala-em-interação}

Resumo: A concepção de identidade pós-estruturalista, em uma perspectiva etnometodológica, trouxe profundas mudanças na maneira como se estabelecem as relações entre gênero e linguagem. Gênero passa a ser entendido como uma construção social que precisa ser (re)negociada a cada nova interação e, por não existir fora do discurso, não tem um status fixo e estável. Para entender como as identidades de gênero são interacionalmente negociadas, e aqui especificamente os aspectos relacionados à maternidade, apresento a importância da Análise da Conversa, através da análise qualitativa de interações naturalísticas entre uma psicóloga e candidatos/as à vasectomia e à laqueadura, em um posto de saúde do SUS, na região Sul do Brasil. O que mostro, através da análise de três excertos, é que pequenas fissuras nas performances de maternidade fazem colidir a noção de uma maternidade estável, o que nos dá uma ideia prática do conceito de agentividade.

Palavras-chave: fala-em-interação; linguagem; identidades; gênero; maternidade.

Copyright @ 2012 by Revista Estudos Feministas.

' Catherine GALLAGNER e Thomas LAQUEUR, 1987.

\section{Introdução}

Para entender melhor o processo de construção social das identidades maternas, julgo útil olhar para alguns discursos que contribuíram (e ainda contribuem) para a naturalização e a homogeneização da maternidade. Falas e ações endossadas pelo discurso científico procuram estabelecer diferenças entre os corpos masculinos e femininos, possivelmente, com o propósito de justificar as diferenças de papéis sociais e, assim, legitimar uma agenda política de poder do homem sobre a mulher. ${ }^{1}$ Como a base dessa diferenciação dos corpos é biológica e o parâmetro da normalidade é o corpo masculino, a partir do qual se mede o feminino como desviante, é retirada, nessa ótica, a importância cultural no processo de construção identitária. 
2 Jakob ACKERMANN citado por GALLAGNER e LAQUEUR, 1987, p. 51.

${ }^{3}$ GALLAGNER e LAQUEUR, 1987.

${ }^{4}$ Note-se que esta concepção pressupõe como dado a existência de atividades essencialmente masculinas, que não são adequadas para as mulheres e que alterariam a sua "feminilidade".

${ }^{5}$ Fabíola ROHDEN, 2001 e 2003.

${ }^{6}$ Londa SCHIEBINGER, 1987.

${ }^{7}$ Não raro os órgãos sexuais femininos são reportados como fracos, passivos, e validade vencida, mais suscetíveis à degeneração, ou seja, se comportam de um modo 'feminino'. Em contrapartida, aos órgãos masculinos são atribuídos qualificadores como força, ação, velocidade e produção quase vitalícia, ou seja, um comportamento 'masculino'. Esse comportamento em nível celular é uma representação, muitas vezes, das relações em contextos macro, naturalizados pelo discurso dito objetivo da ciência (Anne FAUSTO-STERLING, 2000; Paula MACHADO, 2005; e Emily MARTIN, 1996).

${ }^{8}$ Temos inúmeros exemplos sobre como é construída a irracionalidade feminina, comumente atribuída à questão hormonal (Lisa CAPPS, 1999). A tensão prémenstrual (TPM) é um exemplo largamente explorado e divulgado. Ela é ratificada inclusive pela legislação brasileira, que confere atenuantes à mulher infratora durante os dias que antecedem o período menstrual. O interessante é constatar que nem todas as sociedades reconhecem a TPM e que mulheres que passam a viver em sociedades onde ela "existe" passam a apresentar os sintomas. Esse processo é amplamente estudado pela Antropologia Médica e é chamado de "culture bound syndromes" (C. HUGHES, 1996; e Nancy SCHEPER-HUGHES, 1992).

${ }^{9}$ SCHIEBINGER, 1987.

${ }^{10}$ Betty FRIEDAN, 1971.

1 FREUD citado por FRIEDAN, 1971.
A ciência, desde o século XVIII, busca obstinadamente localizar as diferenças sexuais, auscultando ossos, cabelos, cérebros, hormônios, para "descrever de forma essencial as diferenças sexuais, das quais todas as outras brotam". ${ }^{2} \mathrm{O}$ evolucionismo tomou como natural que os homens, em virtude de sua "razão natural de superioridade", dominassem as esferas públicas do governo e do comércio, da ciência e do saber. Já para as mulheres, "criaturas de sentimento", era natural que realizassem seu destino como mães e conservadoras do costume na esfera confinada do lar. As desigualdades sociais eram, portanto, baseadas em "leis" naturais. ${ }^{3}$

Inúmeros tratados médicos procuraram explicar a inaptidão da mulher para o trabalho fora do lar e a atividade intelectual com base em estudos de crânios. A medicina sustentava que o excesso de estudo ou trabalho físico masculinizava ${ }^{4}$ a mulher. ${ }^{5}$ Também desenvolveu complexas teorias que explicavam a função primordial da mulher: a procriação. O tamanho da pélvis era a prova da natureza, traduzida pelos médicos, de que a mulher só se realizaria na maternidade: seu papel social mais importante e sem o qual sua existência não teria justificativa. Já seus ombros mais estreitos eram a prova biológica da sua fragilidade e necessidade de proteção.

O corpo da mulher, não obstante, era comparado ao de uma criança ou de seres primitivos, que teriam estacionado no seu processo evolutivo. ${ }^{6} \mathrm{~A}$ mulher era, também, constantemente associada, na literatura médica dos séculos XVIII e XIX, à fraqueza, ${ }^{7}$ histeria ${ }^{8}$ e predisposição à lascívia, precisando, portanto, da tutela de um homem para protegê-la de si mesma e do mundo. ${ }^{9}$ Friedan ${ }^{10}$ acusa a psicanálise por "explicar" a inferioridade feminina como um destino biológico, ignorando completamente as influências culturais e sociais na construção das identidades de gênero. Para Freud, as características "naturais" da mulher - passividade, masoquismo e narcisismo - estariam ligadas a uma "insuficiência" orgânica que é a ausência do pênis. "

Na década de 1920, surgem as primeiras pesquisas sobre gênero e linguagem, porém é na década de 1990, na também chamada terceira onda dos estudos feministas, que esses estudos promovem um profundo deslocamento epistemológico. Esses estudos, situados no movimento chamado de pós-estruturalista, problematizam a existência de uma realidade ontológica de gênero. ${ }^{12}$ Eles passam a considerar o fato de que os corpos são o espaço de inscrição da história, destacando a linguagem como uma "prática corporeificada". ${ }^{13}$ Esse corpo como instância onde a cultura se inscreve é alvo, então, de todo um sistema de monitoramento executado via discurso, via linguagem. 
12 Judith BUTLER, 1990.

${ }^{13}$ Pierre BOURDIEU, 1998.

${ }^{14}$ Mary BUCHOLTZ e Kira HALL, 2005; BUTLER, 1990; Penelope ECKERT e Sally MCCONNELL-GINET, 1992; Ana Cristina OSTERMANN, 2003 e 2006; Susan SPEER, 2005; e Etiene WENGER, 1998.

${ }^{15}$ Elisabeth BADINTER, 1985.

${ }^{16}$ BADINTER, 1985.
Assumindo a linguagem como prática corporeificada, não se pode mais conceber as identidades de gênero como existentes fora do discurso. Sendo assim, e por não serem naturais, as identidades precisam ser propostas e constantemente negociadas na e pela interação com o/a outro/a, que pode ratificá-las ou não. As interações assumem, então, um papel central na construção das identidades, e gênero passa a ser concebido como uma ação, e não um estado. ${ }^{14}$

Tomando como base o que foi dito até aqui, pretendo olhar, neste estudo, para a (re)negociação da identidade de mãe, tendo como pano de fundo justamente a ideia de que não existem identidades naturais, mas discursos normativos sobre as expectativas de performances de maternidade. Esses discursos normativos são trazidos e atualizados na fala-em-interação, e o que busco ver, através de um aparato teórico-metodológico específico, é como se dá esse processo de (re)negociação dos discursos macrossociais, que se pretendem, muitas vezes, universais e naturais, na esfera micro das conversas mundanas.

Badinter ${ }^{15}$ faz um estudo sócio-histórico da maternidade em diferentes épocas e contextos sociais e aborda a construção social do papel de mãe, desnaturalizando a suposta vocação da mulher para a maternidade. Para ela, a relação mãe e filho/a se desenvolve de acordo com as construções sociais e econômicas em que elas/eles vivem e, com isso, a autora defende que o amor materno não é um sentimento inato nas mulheres.

As mulheres nos séculos XVII e XVIII não se rendiam às mesmas expectativas de maternidade que as mulheres contemporâneas, por exemplo. Ao contrário, muitas delas tratavam com indiferença seus/suas filhos/as, deixando-os/ as aos cuidados de amas de leite nos primeiros anos de vida e, depois, se sobrevivessem, mandavam-nos/as para os internatos e conventos. A maternidade, naquela época, não gozava de prestígio social e as mulheres não obtinham nenhum reconhecimento especial por serem mães.

Somente a partir do final do século XVIII os discursos médicos, teológicos, filosóficos e pedagógicos começam a unificar e universalizar a "maternagem". ${ }^{16}$ Isso, em boa parte, porque as demandas sociais mudaram, com o advento de uma nova organização do Estado. Nessa nova organização, o modelo de obediência ao soberano, que era refletido na célula familiar através da obediência e do temor à figura paterna, cede lugar a uma organização de Estado que precisa de cidadãos/ãs saudáveis e produtivos/as. Para isso era preciso convocar e convencer as mães a cuidarem e educarem pessoalmente seus/suas filhos/as. A mídia e todos os discursos autorizados se empenharam massivamente, a 


\footnotetext{
${ }^{17}$ BADINTER, 1985, p. 325.

${ }^{18}$ FRIEDAN, 1971.

${ }^{19}$ Karin MARTIN, 2003.

${ }^{20}$ BOURDIEU, 1998, p. 18.

${ }^{21}$ ECKERT e McCONNELL-GINET, 1992; OSTERMANN, 2003 e 2006; e WENGER, 1998.

22 BOURDIEU, 1998 e 2003.

${ }^{23}$ e.g. Celia KITZINGER, 2007; OSTERMANN, 2003 e 2006; Mariléia SELL, 2007; e Ann WEATHERALL, 2002.

${ }^{24}$ David SILVERMANN, 1998.
}

partir do século XIX, para construir o que Badinter ${ }^{17}$ chama de "a religião da mãe". Friedan ${ }^{18}$ aponta para o fato de que as mães passaram a ser responsáveis por tudo e por toda a sorte de males que acometessem os/as filhos/as, familiarizando-as, assim, com a culpa.

Martin ${ }^{19}$ fala dos modelos impostos (normalmente por homens) para o exercício da maternidade e menciona a idealização do parto e da amamentação como exemplos de experiências que passaram a ser alvo de uma série de construções romantizadas de alegria e de sublimação da dor. Ela classifica esses modelos como ferramentas que exercem controle sobre os corpos femininos, responsáveis pela naturalização e pela universalização de experiências e sentimentos. Isso, segundo a autora, é um processo de construção social de identidades de gênero que retira a agentividade das mulheres, ou seja, quando as mulheres não sentem aquilo que é esperado delas, há, muitas vezes, um sentimento de inadequação, invalidação, frustração e culpa.

\section{Processos invisíveis de construções identitárias}

Como vimos, os diversos discursos autorizados vão normatizando as performances de gênero, registrando no corpo os traços culturais e tornando-o uma "realidade sexuada". ${ }^{20}$ Assim, homens e mulheres vão aprendendo aquilo que é esperado deles/delas dentro das "comunidades de prática" das quais fazem parte ao longo da vida. ${ }^{21}$ Esse complexo sistema é tão pulverizado, automatizado e naturalizado que se torna impossível atribuir agentes: a ordem das coisas ${ }^{22}$ se encarrega de fazer 0 mundo funcionar dentro de normas culturais arbitrárias que vão se tornando naturais.

Por assumir que as identidades não são naturais e pré-discursivas e que as pessoas reinstanciam e ressignificam o mundo em cada interação, de forma mutuamente orientada, adoto, para a análise dos dados desta pesquisa, - aporte analítico da Análise da Conversa de base etnometodológica (doravante também AC), proposta por Harvey Sacks, e que vem se consolidando cada vez mais em pesquisas na interface linguagem e gênero. ${ }^{23}$ Dentro desse escopo teórico-analítico dois aspectos são fundamentais para os estudos sobre linguagem e gênero: a) a linguagem não é um veículo do pensamento ou um espelho que meramente reflete a realidade, mas ação constitutiva da realidade e b) as identidades de gênero não existem fora do discurso (linguagem).

Para a AC, a interação face a face é a estruturadora da ordem social ${ }^{24}$ e a responsável pela maioria dos arranjos 
${ }^{25}$ Marjorie GOODWIN, 1990.

\footnotetext{
${ }^{26} \mathrm{~A}$ sanidade mental é atestada através da checagem das funções do ego que são: atenção, sensopercepção, inteligência, memória, pensamento (produção, curso e conteúdo), orientação (auto e alopsíquica), linguagem, conduta, consciência e afeto (modulação afetiva) (Karl JASPERS, 2000). O tipo de questionário utilizado para realizar essa testagem pode variar de profissional para profissional.

${ }^{27}$ BRASIL, 1996.

${ }^{28}$ David FETTERMANN, 1998.

${ }^{29}$ Alain COULON, 1995.

${ }^{30}$ Por turno de fala pode-se entender a vez de falar e são considerados turnos de fala desde frases a enunciados não lexicais como o caso do "uhum" ou "Mn" (Harvey SACKS, Emanuel SCHEGLOFF e Gail JEFERSON, 1974).

${ }^{31}$ Cristiane SCHNACK, Thaís PISONI e OSTERMANN, 2005.
}

sociais. ${ }^{25}$ É, então, na ação mundana da fala-em-interação que se dá, para a AC, a perpetuação ou a refutação das concepções naturalizadas de maternidade. Pela peculiaridade analítica, estudos nessa abordagem conseguem se aproximar mais dos métodos utilizados pelos/as participantes para construir e gerenciar a sua conduta em relação às expectativas de performances identitárias. Na fala-eminteração muitos aspectos identitários que são tomados pelo senso comum como homogêneos e estáveis são tensionados e desestabilizados, confirmando justamente o fato de que não existem identidades fora do discurso.

\section{Metodologia}

Os dados examinados neste artigo fazem parte de um corpus de 25 interações entre pacientes aspirantes ao procedimento da vasectomia ou da laqueadura e uma psicóloga em um posto de saúde do Sistema Único de Saúde, localizado em uma das regiões metropolitanas do Sul do Brasil. Trata-se de consultas psicológicas em que os/as pacientes buscam o seu aval de sanidade mental ${ }^{26}$ para conseguirem o direito à esterilização pelo Programa Nacional de Planejamento Familiar. ${ }^{27}$

A pesquisa tem um cunho etnográfico ${ }^{28} \mathrm{e}$ etnometodológico ${ }^{29}$ e está circunscrita em três etapas: a coleta, a transcrição e a análise dos dados. Para a coleta, faço uso de gravações em áudio de interações naturalísticas e anotações em diários de campo. A visão etnometodológica é particularmente importante para os/as analistas da conversa, pois eles/elas examinam como os/as interlocutores/ as se orientam para as atividades em que estão engajados/ as, na movimentação turno a turno das falas. ${ }^{30}$ Essa orientação pode ser acessada através dos dados que, por estarem registrados, armazenados e transcritos dentro de normas convencionais, ${ }^{31}$ são passíveis de checagem por outros/as leitores/as analistas, não dependendo exclusivamente da categorização e da interpretação do/a pesquisador/a.

A análise dos dados busca ver os padrões recorrentes nas interações, ou seja, busca ver o que acontece reiteradamente na forma como os/as envolvidos/as negociam suas identidades de gênero, especialmente os aspectos relacionados à performance da maternidade, por intermédio de marcas sociointeracionais.

\section{Da estabilidade à fissura: o exercício da agentividade nas (re)construções identitárias}

A presente seção traz três excertos em que os/as participantes (dois homens e uma mulher) negociam, por 
32 JASPERS, 2000.

${ }^{33}$ Ian Hutchby e Robin Wooffitt (1998) definem formulação como uma ação de síntese/explicação daquilo que foi trazido à conversa em turnos anteriores.

${ }^{34}$ Lorenza MONDADA, 1998.

35 Johanna RUUSUVUORI, 2005. meio da fala, concepções e construções de gênero, que vêm, muitas vezes, coladas às identidades de ser pai e de ser mãe. Discursos que operam nos contextos sociais mais amplos são trazidos e atualizados na arena da interação face a face, e esse processo pode acontecer por meio de alinhamento ou resistência. Isso prova que as identidades não gozam de um status natural, mas exigem a constante ratificação do/a outro/a.

Na primeira parte da consulta, a psicóloga coleta e anota informações como: a) profissão; b) endereço; c) número de filhos/a e suas idades; e d) renda individual e familiar. Após esse questionário inicial, a psicóloga pergunta sobre a participação prévia na palestra sobre os métodos de contracepção, que é obrigatória para os/as interessados em fazer a vasectomia ou a laqueadura. A segunda parte da consulta se caracteriza por questões mais subjetivas como: a) como você se vê; b) você consegue identificar quatro qualidades e quatro defeitos em você; c) que evento da infância o/a marcou; d) você consegue identificar quatro qualidades e quatro defeitos em seu pai e em sua mãe; e e) o que você acha que herdou de seu pai e de sua mãe. Para finalizar, a psicóloga solicita aos/às pacientes que esses/ essas façam o desenho de uma pessoa em uma folha em branco. A pauta da psicóloga, é importante lembrar, tem por finalidade avaliar as condições de sanidade mental do/a paciente, através da checagem das funções do ego. ${ }^{32}$

A interação entre Bina (como passarei a chamar a psicóloga) e os/as pacientes é organizada sequencialmente nos pares adjacentes pergunta/resposta e estruturada no formato de entrevista. Bina faz as perguntas e os/as pacientes respondem, o que demonstra que esses/essas ratificam a identidade social da terapeuta e se alinham sem resistência a essa atividade. Bina, na maior parte das vezes, adota a postura de ouvinte silenciosa, produzindo respostas mínimas apenas, repassando, assim, o turno de fala de volta ao/à seu/sua interlocutor/a. Essa postura possibilita que os/as pacientes façam formulações ${ }^{33}$ maiores e mais detalhadas. O silêncio não é tomado como problemático na consulta terapêutica, pois os/as envolvidos/as sabem que esse é um elemento pertencente ao gênero interacional ${ }^{34}$ em questão. Atitudes de Bina como o silêncio, o uso de elementos lexicais que funcionam como continuadores (uhum) e a não interrupção durante a fala dos/as pacientes podem ser tomadas como atividades centradas no/a paciente. ${ }^{35}$

Os dois primeiros excertos trazem a construção mais estável e homogênea da maternidade, ou seja, os pacientes trazem à esfera da fala-em-interação performances socialmente ratificadas e que não geram tensão entre os/as interlocutores. 
(1) $[12 / 02 / 2007 ; 0-331]$

221 BINA:

222

223 RICHARD:

224 BINA:

225 RICHARD:

226 BINA:

227

228 RICHARD:

229

230 BINA:

231 RICHARD:

232

233

234

235

236

237 BINA:

238 RICHARD:

239

240

241

242

243

244

245

246

247

248

249

250

251 BINA:

252 RICHARD:

253 BINA:

254 RICHARD:

255 BINA:

256

257

258 RICHARD:

259

260 RICHARD:

261 BINA:

262

263 BINA:

264 RICHARD: .hhh ãh::: (.) me cita duas qualidades e dois

defeitos do teu pai $\downarrow$

'en $\uparrow$ tão ${ }^{\circ}$ meu pai é suici $\uparrow d a($.

e-

${ }^{\circ} x x^{\circ}$ (fala incompreensível)

como é que ele era $\uparrow$ assim ã duas coisas boas e

duas coisas ruins $<$ [dele] $>$

[tá $\uparrow$ ] duas coisas ruins $>$ que

eu achava< é:: que ele:: ele bebia muito né $\uparrow$

ouhum ${ }^{\circ}$

bebia muito, (.) fumava (.) é:: vício né $\uparrow$ eu::

não sou muito chegado no vício ${ }^{\circ}$ eu não gosto $x x^{\circ}$

(2.0) qualidade (ele tinha era) um homem

trabalhado:r (.) e atencioso também $>$ com $a<$ com a

família ${ }^{\circ} \operatorname{assim}^{\circ}(1.0)^{\circ} \mathrm{x} x x x x x^{\circ}$

(3.0)

e a mãe?

minha mã::e (. $)^{\circ}$ defeito (dela) ${ }^{\circ}$ geralmente as mãe

não tem defeitoné? @@ @ @.hh a gente não

enxerga muito os defeito das mã- da mãe $\uparrow$ mas

minha mãe $\uparrow$ deixe me vê $\uparrow$ (.) também de repente uma

hora que:: (.) é:::: ela achava que talvez (.)

passava pela cabeça de um outro irmã::o, uma

coisa assim talvez $\uparrow$ (.) (de repente ela:::) $\uparrow$

porque mã::e $\uparrow$ (1.0) minha mãe é uma pessoa $\uparrow$ (1.0)

defeito de minha mãe $\uparrow$ deixe me vê个@@@ @.hh(2.0)

<talvez> é::.::: achá que::::: > um outro irmão

tenha feito um é: (tu tá) errado e ela achá que

não né $\uparrow$ no caso vamo dizê passá xx- a mão pela

cabe $[c ̧ a]<\uparrow$

[uhum]

isso seria é: um de[feito]?

[uhu:m]

outro < defe:ito> (6.0) talvez (3.0)

${ }^{\circ} x x x x^{\circ}$

(7.0)

$\mathrm{xx} x \mathrm{xx}$

tá

(2.0)

$x x x x x x \uparrow$

uh[um]

(2.0)

e qualidade?

é uma pessoa que:: atendia um monte de gente lá 
265

266 BINA:

267 RICHARD: no xxxx, [e::] (.) sempre alegre também $\uparrow$

[uhum]

uma pessoa alegre

\footnotetext{
${ }^{36} \mathrm{~A}$ ação de prever um julgamento negativo e se defender dele é nomeada pela Psicologia Discursiva como inoculação (Jonathan POTTER, 1996).

37 HUTCHBY e WOOFFITT, 1998; Harvey SACKS, 1992; e SILVERMANN, 1998.
}

Na linha 221, Bina pede para Richard citar duas qualidades e dois defeitos do pai. Richard responde imediatamente que o pai é suicida. Nas linhas 226 e 227 , Bina repete a pergunta e pede duas "coisas boas" e duas "coisas ruins" do pai. Richard parece ter bem presentes os defeitos do pai ao emitir, em fala sobreposta (linha 228), um "tá" (ascendente), que, nesse contexto sequencial, sinaliza resolução em falar.

O paciente decide iniciar pelas coisas ruins, não seguindo a ordem proposta por Bina, que era de citar primeiro duas coisas boas. Na linha 229, Richard menciona a bebida como uma coisa ruim e prossegue, na linha 231 , reafirmando que o pai bebia muito e fumava também. Ele categoriza essas atividades como sendo um vício e na linha 232 se defende ${ }^{36}$ da possibilidade de ser associado ao pai nos aspectos negativos, ao dizer que "não é muito chegado no vício e que não gosta disso". Richard está, aqui, negociando sua identidade moral ${ }^{37}$ de homem sóbrio. Richard precisa de três turnos para elaborar as qualidades do pai (linhas 233, 234 e 235) e mais três segundos (linha 236), o que sinaliza que o tópico é tomado por ele como problemático. Contudo, para apontar os defeitos do pai, Richard providencia falas imediatamente, não demandando de tempo para iniciar sua ação (linhas 223, 228, 229 e 231).

Quando Bina pergunta da mãe (linha 237), Richard precisa de 13 turnos de fala para elaborar um defeito dela. Apesar de toda essa carga semântica, ele sinaliza, na linha 252 , que não tem certeza de que aquilo que apontara é realmente um defeito e solicita a confirmação de Bina. Richard ainda associa à categoria mãe a ação de não ter defeitos, ou se elas (as mães) os têm, "a gente não enxerga" (linhas 239 e 240). Mesmo o defeito de "passar a mão na cabeça" envolve uma ação protetora, tratando-se, portanto, de um defeito perdoável, comumente associado às mães. Ao retomar sua busca por defeitos na mãe, Richard produz silêncios (linhas 254 e 256), faz nova tentativa de nomear defeitos ao providenciar um "tá" (linha 258), mas produz sons desarticulados que não chegam a formar palavras, e mais silêncio, na linha 262.

Bina resolve mudar de tópico e pergunta das qualidades da mãe, ao que Richard responde imediatamente que ela é "alegre" e que "atendia um monte de gente" (linhas 264 e 265). Quando Bina Ihe repassa o turno de fala, depois 
38 "Empacotamento", segundo Anita Pomerantz e B. Fehr (1997), é o meio pelo qual o/a falante realiza suas ações. Importante ressaltar que diferentes empacotamentos provocam diferentes reações no/a interlocutor/a. Se eu disser, por exemplo, que estou com fome, meu interlocutor pode "empacotar" minha asserção como um pedido de comida ou, dependendo do contexto, como um pedido de apressar alguma atividade para, então, comer e assim por diante.

\section{(2) $[21 / 02 / 07 ; 0-322]$}

260 BINA:

261 MARCELO:

262 BINA:

263

264

265

266

267 MARCELO:

268

269 BINA:

270 MARCELO:

271

272 BINA:

273 MARCELO:

274

275 BINA:

276

277 MARCELO:

278

279 BINA:

280 MARCELO:

281 da expressão "uhum" (linha 266), ele formula, na linha 267, que a mãe era uma pessoa alegre, empacotando ${ }^{38}$ a ação de descrever a mãe.

É interessante notar a extensa investida interacional de Richard, marcada por silêncios, reparos, alongamentos, pausas e falas incompreensíveis, para elaborar os defeitos da mãe, que, ao fim e ao cabo, resultam na descrição de algo que Richard tem dificuldade em categorizar como defeito. Dito de outra forma, Richard não tem certeza se "passar a mão na cabeça" é, de fato, um defeito. Isso pode estar relacionado à assunção de que mães não têm defeito, trazida por Richard e que é, de certa forma, uma abstração do senso comum. A sacralização das mães é largamente explorada na literatura, que traz a figura materna como abnegada (o que o próprio Richard traz quando fala que a mãe atendia um monte de gente) e protetora (quando "passa a mão na cabeça").

No segundo excerto Marcelo também constrói a sua mãe sem tensionar as expectativas de performances de maternidade operantes naquela comunidade de prática. O que é interessante notar é que, a exemplo do que aconteceu na primeira interação, Marcelo não dispensa tanto cuidado linguístico ao falar do pai. e que você aprendeu com eles?

eu apren[di:-]

[por] exemplo $\uparrow>$ você diz que você é

brincalhão, é alegre, é estressa:do < .h é:::

xinga muito, mente de vez em qua::ndo, (.) isso

tu aprendeu isso de quem?

(1.0)

não $\uparrow$ mas não foi ele- não foi deles $\uparrow$ (1.0) ${ }^{\circ}$ não foi

eles $^{\circ}$

○@

xx- qué dizê:: $\uparrow$ às vez meu pai aplica uma

mentirinha mas xx- também é só pra:

vi:[:u]?

[é:] $\uparrow$ mas não é assim de:-

(3.0)

então tu aprendeu isso do teu pai? (.) aplicá

mentira?

'éo

(2.0)

e da mãe?

'da mãe é difícil ${ }^{\circ}$ (8.0) minha mãe nunca fe::z

(.) nunca fez mal pra ninguém (nunca) $\uparrow$ 
39 Uma das atividades dos/as terapeutas é o gatekeeping (Frederick ERICKSON e Jeffrey SCHULTZ, 1982), que pode ser definido como a ação de chancelar ou dar os contornos da atividade interacional na qual paciente e terapeuta estão engajados/as.

${ }^{40}$ HUTCHBY e WOOFFITT, 1998; SACKS, 1992; e SILVERMANN, 1998.

${ }^{41} \mathrm{O}$ uso da conjunção adversativa "mas" poderia querer dizer que "o pai mente, mas não faz isso sempre" ou ainda que "ele tem tantas qualidades que a mentira ocasional não chega a ser um defeito".

${ }^{42}$ Fishing device (POMERANTZ, 1980) é a ação de 'pescar' informações do/a paciente para que o/a terapeuta possa se munir para fazer formulações e inferências posteriores.
Na linha 260, Bina pergunta sobre o que Marcelo aprendeu com eles (o pai e a mãe). Ele começa a formular a resposta, na linha 261, e Bina produz uma fala sobreposta (linha 262) para dar exemplos do que ele poderia ter aprendido. Ao fazer isso, Bina recupera elementos trazidos por Marcelo no início da interação, quando ele é solicitado a falar de si mesmo e de como se percebe como pessoa. Bina resgata os qualificadores "brincalhão, alegre, estressado, xinga muito, mente de vez em quando" e pergunta com quem ele aprendeu isso, fazendo, assim, um chancelamento ${ }^{39}$ das atividades interacionais.

Bina pode estar ainda engajada na ação de elaborar, com Marcelo, os defeitos do pai e da mãe do paciente, o que até aqui não havia sido alcançado interacionalmente. Marcelo está atento a essa investida de Bina e responde, na linha 267, que "não foi deles" a herança dos qualificadores relembrados por Bina e, após um segundo de silêncio, repete, num volume de voz mais baixo, "não foi eles". Bina responde com uma risada, sinalizando, possivelmente, incredulidade. Marcelo se orienta para essa incredulidade e provê, na linha 270 , uma resposta com a expressão alongada "qué dizê", usada como prefácio de uma (re)formulação de algo que foi dito antes. Interessante notar que Marcelo está orientado para a risada (avaliadora?) de Bina e volta ao tópico numa possível investida de ser levado a sério. ${ }^{40}$ Após o prefácio da linha 270, Marcelo elabora um defeito do pai - "às vezes meu pai aplica uma mentirinha" (linhas 270 e 271) - e usa a conjunção adversativa "mas", ${ }^{41}$ que denota compensação ou contraste, na expressão atenuante "também é só pra" (linha 271).

Bina interrompe a fala atenuante de Marcelo e, na linha 272, produz a expressão "viu", num volume de voz mais alto e de forma alongada. Bina estava na investida interacional de fazer Marcelo elaborar os defeitos do pai e da mãe, o que ela conseguiu ao pescar ${ }^{42}$ elementos que ele já havia trazido para a interação. A expressão "viu" é também sinalizadora da relação hierárquica entre Bina e Marcelo, pois Bina está, nessa interação, avaliando o paciente e, está, portanto, na posição de emitir argumentos de autoridade. É interessante notar que o uso do "viu" é também comum a pessoas que desempenham outros papéis sociais como professores/as, pais/mães, médicos/as. O uso está, assim, relacionado à posição hierárquica do/a falante.

Marcelo está atento para o fato de que a construção da identidade moral do pai está acontecendo e, na linha 273 , ele procura justificar com "mas não é assim de" e não termina de elaborar a fala, seguindo um silêncio de três segundos (linha 274). Nas linhas 275 e 276, Bina faz a formulação "então tu aprendeu isso do teu pai? aplicá 
${ }^{43}$ Os nomes de todos/as os/as participantes, bem como de logradouros, cidades ou aspectos que pudessem denunciar a identidade dos/as envolvidos/as nesta pesquisa, foram alterados. ${ }^{44} A$ resistência ou negação de determinada identidade pode ser notada através da indexicalização linguística que o/a falante faz para se "colar" a outro grupo social ao qual gostaria de se afiliar. Essa resistência pode estar relacionada a questões de poder, status e reconhecimento. mentira?". Marcelo responde, na linha 277, com a expressão "é", ao que segue um silêncio de dois segundos, que Bina interrompe com a pergunta "e da mãe?" (linha 279). Marcelo responde imediatamente que "da mãe é difícil" (linha 280). Após essa afirmação, Marcelo fica em silêncio por oito segundos e continua a negociação da identidade moral da mãe com a expressão "minha mãe nunca fez mal pra ninguém" (linhas 280 e 281), o que enfatiza reafirmando o intensificador "nunca" em tom ascendente.

Durante quase a totalidade da interação, Marcelo tem dificuldade em nomear os defeitos do pai. Quando, após uma longa investida interacional, Marcelo atribui o defeito da mentira ao pai, ele imediatamente nega que a mãe também tenha esse defeito. Marcelo se orienta, ainda, para a mentira como algo "que faz mal" (linha 281), ao dizer que a mãe nunca fez mal a ninguém. Ou seja, as atividades mentir e fazer mal não estão, para Marcelo, vinculadas à categoria mãe, mas ele reconhece essas atividades na categoria pai.

A próxima interação mostra como a paciente Donna ${ }^{43}$ e a psicóloga Bina constroem colaborativamente as performances de maternidade. Ao passo que a paciente avalia a mãe, ela traz suas expectativas em relação a essa categoria. Ao longo da interação, Donna, a paciente, descreve vários defeitos do pai e da mãe e, ao ser indagada sobre o que havia herdado dele e dela, ela imediatamente responde que nada. Essa não afiliação ${ }^{44} \mathrm{com}$ o pai e a mãe é constitutiva da negociação da própria posição identitária de mãe que a paciente está construindo e evocando para si.

\section{( 3 ) $[12 / 02 / 07 ; 0-662]$}

\section{BINA:}

563

564

565

566

567 DONNA:

568

569

570

571

572

573

574

575

576 BINA: então tá $\downarrow$ e o que que a mãe tem de bo::m?

(14.0)

não acha nada?

(4.0)

nem quando era pequena ${ }^{\circ}$ assim tu não lembra?

nãole $\uparrow m b r o \uparrow$

(6.0)

não gosto de falá mal da mãe eu atendo ela, alcanço as coisa pra ela, sempre ajudo ela $\uparrow$ (.) mas (erro) dela foi que o vô me ensinou assim $\uparrow$

(.) foi- $x x x x x$ ela nunca:: (.) se morrê a gente enterra ela sempre diz $\uparrow$ ela nunca:: (.) nunca chamô nenhum de nós de meu filho, minha filha, nun::ca >nunca nunca nunca nunca< ouhum 
577 DONNA:

578

579

580

581

582

583

584 BINA:

585 DONNA:

586

587

588 BINA:

589 DONNA:

590

591 BINA:

592 DONNA:

593

594

595

596

597 BINA:

598 DONNA:

599 BINA:

600

601 DONNA: que nem a gente e::u- lá em casa eu trato o dino diferente e a nana a gente brinca, a gente vai na pracinha, a gente (.) diz eu te amo, e boa noite meu filho, e beija, e: abraça:: e:: em casa não era assim $\downarrow$ (.) não sei $\uparrow$ também não se $\uparrow$ i se deu tempo $\uparrow$ é que daí também $\uparrow$ a minha irmã tinha câncer, eles corriam muito, = uhum que também não era fácil né $\uparrow$ a minha mãe acho que ficou ama::rga $\uparrow$ é que eu não me lembro da minha mãe antes da celine ficá doente $\downarrow$

uh[um]

[só] me lembro depois $\downarrow$ que eu era muito pequena $\downarrow$

uhu::m

entã::o depois ela talvez ela tenha sido depois

que ela ficou muito amarga $\downarrow$ (.) ela pensa porque eu fiquei doente que eu perdi uma na gestação $\uparrow$ imagina se eu tivesse ficado $\uparrow$ [per]dido uma com seis anos eu

[sei]

acho que eu [tinha morrido]

[provavelmente] é: a a: deve tê afetado

[é::]
${ }^{45} \mathrm{~A}$ pergunta fechada delimita as possibilidades de resposta (RUUSUVUORI, 2005), já as perguntas abertas oferecem um espaço maior aos/às pacientes para elaborarem suas respostas.

${ }^{46}$ SACKS, 1992; e SILVERMANN, 1998.

${ }^{47}$ Erving GOFFMAN, 1999.
Ao ser questionada sobre o que a mãe tem de bom (linha 562), Donna permanece em silêncio por 14 segundos. Quando Bina pergunta se ela não acha nada (linha 564), Donna continua em silêncio por mais quatro segundos. Bina insiste e elabora uma pergunta fechada: 45 "nem quando era pequena... tu não lembra?" (linha 566). A paciente se orienta para a pergunta delimitadora e responde com uma das possibilidades "não lembro". Após a resposta da paciente, Bina permanece em silêncio, o que significa que o turno de fala continua com Donna. A paciente percebe 0 turno como seu e começa a providenciar uma resposta, depois de seis segundos de silêncio (linha 568).

Na linha 569, Donna começa justificando que não gosta de falar mal da mãe. Falar mal da mãe é, assim, abordado como tabu, ou seja, algo que se reprime por gerar sentimentos conflitantes com a ordem moral local, ${ }^{46}$ que é a de falar bem da mãe. Donna está atenta a esse tabu e inicia sua fala com uma proteção de face, ${ }^{47}$ ao dizer que não gosta de falar mal da mãe. Antes de mencionar os 
${ }^{48}$ A Psicologia Discursiva descreve a estratégia de se defender de inferências negativas como stake inoculation (e.g. POTTER, 2004).

${ }^{49}$ SACKS, 1992.

${ }^{50}$ Essa afirmação de Donna parece remeter a um dos maiores tabus da humanidade: a morte. A morte social (Rachel MENEZES, 2004), muito mais que a morte individual (singular), representa a privação dos direitos e das relações sociais que na nossa cultura são tidos como um mecanismo essencial para a "boa morte".

${ }^{51} \mathrm{O}$ uso de generalizadores é, normalmente, um apelo mais retórico do que, de fato, a representação quantificada da realidade (SILVERMAN, 1998).

52 Escuta ativa (HUTCHBY, 2005; e MONDADA, 1998) é uma atividade terapêutica que implica a escuta atenta da/o terapeuta para ajudar na solução do problema da paciente.

${ }^{53}$ ECKERT e McCONELL-GINET, 1992. defeitos, Donna ainda diz que "atende ela" (linha 569), que "alcança as coisas pra ela" e que "ajuda ela" (linha 570). Donna está, aqui, negociando sua identidade moral de filha, que não deixaria de atender a mãe, apesar de se tratar de uma mãe com muitos defeitos, ou seja, ela está se "inoculando" 48 de uma possível avaliação negativa por parte da psicóloga. A identidade de filha é tornada relevante na conversa em relação ao seu par relacional, a mãe, ou seja, Donna deixa claro que cumpre com as suas obrigações de filha. As identidades negociadas surgem, então, como o loci de uma série de direitos e obrigações. ${ }^{49}$

Na linha 571, Donna começa a falar em "erro" da mãe e, novamente, antes de nomear os erros, ela diz que, se a mãe morrer, "a gente enterra ela", ou seja, não será tratada como uma indigente. ${ }^{50}$ Finalmente, depois de 10 turnos de fala, na linha 573, Donna começa com o uso do intensificador e generalizador ${ }^{51}$ "nunca" para dizer que a mãe nunca chamou seus filhos de meu/minha filho/a e repete, por cinco vezes, a palavra "nunca" (linha 575). Bina demonstra escuta ativa ${ }^{52}$ ao expressar um "uhum" (linha 576), que tem, na sequência interacional, a função de continuador, ao devolver o turno de fala à Donna. Nesse momento da interação, Donna começa a negociar a sua própria identidade de mãe (linha 577), o que, para ela, envolve "tratar diferente, brincar, ir na pracinha, dizer eu te amo, dizer boa noite meu filho, beijar e abraçar", ou seja, tudo o que ela nunca teve como filha (linhas 578, 579, 580 e 581). Esses usos sociolinguísticos de Donna são, como afirmam Eckert e McConnell-Ginet, ${ }^{53}$ marcas de afirmação de pertencimento a um grupo ou revelam a vontade de pertencer ao grupo legitimado, nesse caso, o das mães que têm determinados comportamentos com os/as filhos/as, ou seja, os comportamentos que estão em conformidade com as convenções sociais.

Depois de apontar a carência que sentia em relação à mãe, Donna começa uma longa elaboração para justificar o comportamento ausente da mãe. Donna aponta a falta de tempo do pai e da mãe porque eles "corriam muito" com a irmã que tinha câncer (linhas 582 e 583). Depois do "uhum" de Bina (linha 584), Donna continua elaborando a justificativa da "amargura" da mãe (linha 586) e diz que não se lembra de como era antes de a irmã adoecer, porque ela era muito pequena (linha 590). Aqui é possível inferir que talvez a mãe de Donna fosse diferente antes de a filha adoecer, pois Donna não lembra. Nas linhas 592 e 593, ela reafirma que talvez tenha sido essa a causa da amargura da mãe e compara o sofrimento da mãe que perdeu uma filha com seis anos de idade com o seu próprio sofrimento ao perder uma filha durante a gestação. Ela conclui dizendo que, se tivesse 
54 MARTIN, 2003.

${ }^{55}$ MARTIN, 2003, p. 67.

56 ECKERT e McCONNELL-GINET, 1992.

57 Candace WEST e Don ZIMMERMAN, 1983. passado pela situação da mãe, teria morrido. Bina se afilia à justificativa de Donna (linhas 599 e 600), sugerindo que provavelmente a perda da filha "deve ter afetado" a mãe de Donna. Donna concorda e diz "é" (linha 601).

É interessante notar que a justificativa da amargura da mãe de Donna é colaborativamente construída entre psicóloga e paciente. Esse desvio do comportamento generificado de ser mãe é desculpado, o que, de certa forma, promove a restauração do comportamento normal de mãe ${ }^{54}$ e não quebra as tecnologias de gênero internalizadas ou, "ao menos, elas são rapidamente restauradas". ${ }^{55}$

A mãe de Donna é absolvida, ao longo da interação, pelo seu comportamento desviante, talvez porque ela tenha cumprido um papel ainda mais arquetípico das mães: o sacrifício. A mãe de Donna passava o tempo inteiro correndo com a filha com câncer. Sacrificou, portanto, seu tempo para tentar salvar uma filha. O que em nenhum momento é construído na interação é a possibilidade de a categoria mãe não desempenhar as atividades esperadas, elencadas por Donna. Bina, na linha 566, também parece não tomar como dado que as mães não tenham nada de bom, nem que seja quando suas crianças são pequenas. Dito de outra forma, a categoria mãe está ligada a certas atividades que, quando não desempenhadas, precisam de uma justificativa maior para que a identidade moral de mãe não fique comprometida. É interessante notar que a mãe de Donna foi, de alguma forma, reinserida nos moldes da mãe idealizada. Parece não ocorrer, nem para a paciente e nem para a psicóloga, que a mãe de Donna talvez estivesse contestando as relações e as atribuições de gênero, pois, como lembram Eckert e McConell-Ginet, ${ }^{56}$ são os/as agentes humanos/as que criam, sustentam e às vezes mudam a sociedade e suas instituições, inclusive gênero e linguagem.

Este último excerto nos traz, então, um exemplo de que as construções identitárias nem sempre se orientam para aquilo que é socialmente ratificado em determinadas comunidades de prática. São essas pequenas brechas que vão trazendo infiltrações e desestabilizando identidades construídas de forma mais estável, e é nesse movimento que as pessoas exercitam a sua agentividade no mundo.

\section{Considerações finais}

A presente pesquisa investigou como os/as pacientes de consultas terapêuticas negociam suas identidades de gênero, enquanto negociam também um atestado de sanidade mental. West e Zimmerman ${ }^{57}$ afirmam que uma das coisas mais universais que os/as humanos/as fazem é gênero. Simples ações como dividir crianças em filas de 
${ }^{58}$ Seen but unnoticed.

${ }^{59}$ WEATHERALL, 2002.

${ }^{60}$ Omnirelevant.

${ }^{61}$ BUCHOLTZ, 1993.

62 BUTLER, 1990 e 1993.

63 John AUSTIN, 1962.

${ }^{64}$ Deborah CAMERON, 2005. meninos e meninas, por exemplo, são praticadas com tanta naturalidade que "são vistas, mas não percebidas" ${ }^{58}$ Dessa forma, as práticas generificadas se tornam universais e, ao mesmo tempo, escondidas, o que faz Weatherall ${ }^{59}$ defender a ideia de que gênero é "omnirrelevante" 60 na interação, mesmo que implicitamente.

A maternidade como um exercício de abnegação, doação e quase santidade é reforçada tanto por homens quanto por mulheres nesta pesquisa. Quando surge uma ameaça de rompimento desse padrão, há um esforço compartilhado entre a psicóloga e os/as pacientes para restabelecer a homogeneidade da performance da identidade materna, não sendo admitida uma versão diversa daquela imaginada pelo senso comum. Mães que não brincam com os/as filhos/as, que não dizem "eu te amo" e que não dizem "meu/minha filho/a" precisam ser "reformadas" através do discurso, pois elas contradizem o protótipo de "mãe". Assim, enquanto alguns aspectos identitários tendem a ser mantidos, outros sofrem deslocamentos e sua homogeneidade é desmontada. Esse movimento de desestabilização é, na verdade, o balanço entre as macroestruturas e a agentividade de cada um/uma, de que Bucholtz ${ }^{61}$ e Butler ${ }^{62}$ falam. A ideia de performatividade, cunhada por Austin ${ }^{63} \mathrm{e}$ reelaborada por Butler nos estudos sobre gênero e linguagem, assume que gênero é uma (re)ação e (re)experimentação de uma série de significados sociais de gênero já estabelecidos. Dessa forma, qualquer identidade prototípica pode ser performada de uma forma diferente, como, por exemplo, a maternidade exercida pela mãe de Donna. A performatividade não coloca homens e mulheres como passíveis receptáculos da cultura nem como seres determinados biologicamente. Eles/elas são agentes que "estilizam" ativamente a sua identidade, em vez de simplesmente reproduzirem identidades de gênero previamente assimiladas.

A realidade intrínseca das categorias naturais carece de sustentação epistemológica, e o ceticismo acerca das grandes narrativas ${ }^{64}$ abre crateras nas identidades lisas, monolíticas e estáveis. São as grandes narrativas, tais como textos médicos, livros de autoajuda, falas que "explicam" o ser homem e o ser mulher, que providenciam explicações universais sobre as "diferenças" entre os gêneros. Essas narrativas universalizantes não dão conta da complexidade das relações sociais e da diversidade de identidades que cada pessoa performa a cada nova interação ao longo da sua vida. Diversidade é, aliás, o grande mote da abordagem teórica pós-estruturalista, que não divide mais homens e mulheres em duas categorias uniformes, mas contempla as múltiplas possibilidades coexistentes intra e intergêneros. 
${ }^{65}$ Podemos, aqui, citar inúmeros exemplos de livros que tentam explicar a "diferença essencial entre homens e mulheres": Homens são de Marte, mulheres são de Vênus, de John Gray; Por que os homens fazem sexo e as mulheres fazem amor, de Allan e Bárbara Pease; Por que os homens mentem e as mulheres choram?, de Allan e Bárbara Pease, entre outros.

${ }^{66}$ CAMERON, 2005, p. 500.
Gênero, por estar atravessado por elementos como etnia, raça, situação socioeconômica, escolaridade, nacionalidade, profissão, entre outros, inviabiliza a grande narrativa e assume, na visão pós-estruturalista, sua vocação para contar múltiplas e complexas narrativas. O que acontece, no entanto, é que se verifica uma preferência do grande público por grandes narrativas. Livros que abordam as questões de gênero e que estouram no mercado editorial continuam explorando a ideia já abandonada pelas feministas pós-estruturalistas da diferença apriorística entre os gêneros, baseando-se em explicações de ordem biológica, em vez de buscar respostas no construcionismo social. Livros que "explicam" a diferença entre homens e mulheres, ${ }^{65} \mathrm{com}$ a finalidade de melhorar a relação entre os sexos, representam, assim, uma revisitação às explicações biológicas e se concentram na área que Deborah Cameron ${ }^{66}$ chama de "nova ciência darwinista da psicologia evolucionista pop". Essa situação remete os/as pesquisadores/ as que estudam a relação gênero e linguagem ao desafio de desenvolver estratégias para tornar atrativas as múltiplas narrativas para a grande plateia. O que se verifica, na verdade, é uma distância abissal entre a percepção de gênero dos/as pesquisadores/as e das pessoas que operam com as noções do senso comum.

\section{Referências}

AUSTIN, John L. How to Do Things with Words. Cambridge, MA: Harvard University Press, 1962.

BADINTER, Elizabeth. Um amor conquistado: o mito do amor materno. Rio de Janeiro: Nova Fronteira, 1985.

BOURDIEU, Pierre. A economia das trocas simbólicas. São Paulo: Perspectiva, 1998.

. A dominação masculina. Rio de Janeiro: Bertrand Brasil, 2003.

BRASIL. Lei n. 9.263, de 12 de janeiro de 1996. Disponível em: <http://www.planalto.gov.br/ccivil/LEIS/L9263.htm>. Acesso em: 16 fev. 2007.

BUCHOLTZ, Mary. "The Mixed Discourse Genre as a Social Resource for Participants." Berkeley Linguistics Society, p. 40-51, 1993.

BUCHOLTZ, Mary; HALL, Kira. "Identity and Interaction: A Sociocultural Linguistic Approach." Discourse Studies, London, v. 7, n. 4-5, p. 585-614, 2005.

BUCHOLTZ, Mary; LIANG, Anita C.; SUTTON, Laurel A. (Ed.). Reinventing Identities: The Gendered Self in Discourse. New York: Oxford University Press, 1999.

BUTLER, Judith. Gender Trouble: Feminism and the Subversion of Identity. New York: Routledge, 1990. 
. Bodies that Matter: On the Discursive Limits of "Sex". New York: Routledge, 1993.

CAMERON, Deborah. "Language, Gender, and Sexuality: Current Issues and New Directions." Applied Linguistics, Oxford, v. 26, n. 4, p. 482-502, 2005.

CAPPS, Lisa. "Constructing the Irrational Woman: Narrative Interaction and Agoraphobic Identity." In: BUCHOLTZ, Mary; LIANG, A. C.; SUTTON, Laurel A. (Ed.). Reinventing Identities: The Gendered Self in Discourse. New York: Oxford University Press, 1999.

COULON, Alain. Etnometodologia. Petrópolis: Vozes, 1995.

ECKERT, Penelope; McCONNELL-GINET, Sally. "Think Practically and Look Locally: Language and Gender as CommunityBased Practice." Annual Review of Anthropology, New York, v. 21 , p. 461-490, 1992.

ERICKSON, Frederick; SCHULTZ, Jeffrey. The Counselor as Gatekeeper: Social Interaction in Interviews. New York: Academic Press, 1982.

FAUSTO-STERLING, Anne. Sexing the Body: Gender Politics and the Construction of Sexuality. New York: Basic Books, 2000.

FETTERMAN, David M. Ethnography Step by Step. London: Sage, 1998.

FRIEDAN, Betty. Mística feminina. Petrópolis: Vozes, 1971.

GALLAGNER, Catherine; LAQUEUR, Thomas. The Making of the Modern Body. Londres: University of California Press, 1987.

GOFFMAN, Erving. The Presentation of the Self in Everyday Life. New York: Anchor Books, 1959.

. "On Face-Work: An Analysis of Ritual Elements in Social Interaction." In: JAWORSKI, Adam; COUPLAND, Nikolas. The Discourse Reader. London: Routledge, 1999.

GOODWIN, Marjorie H. He-Said-She-Said: Talk as Social Organization among Black Children. Bloomington: Indiana University Press, 1990.

HUGHES, C. "Etnopsychiatry." In: SARGENT, Carolyn; JOHNSON, Thomas (Org.). Medical Anthropology: Contemporary Theory and Method. London: Westport Connecticut, 1996.

HUTCHBY, Ian. "Active Listening: Formulations and the Elicitation of Feelings-talk in Child Counselling." Research on Language and Social Interaction, v. 38, n. 3, p. 303329, 2005.

HUTCHBY, Ian; WOOFFITT, Robin. Conversation Analysis. Cambridge: Polity Press, 1998.

JASPERS, Karl. Psicopatologia geral. São Paulo: Atheneu, 2000.

KITZINGER, Celia. "Is 'Woman' always Relevantly Gendered?" Gender and Language, v. 1, p. 39-49, 2007.

MACHADO, Paula S. "O sexo dos anjos: um olhar sobre a anatomia e a produção do sexo (como se fosse) natural". Cadernos Pagu, Campinas, n. 24, 2005. 
MARTIN, Emily. The Egg and the Sperm: How Science has Constructed a Romance based on Stereotypical MaleFemale Roles. Chicago: University of Chicago Press, 1996.

MARTIN, Karin A. "Giving Birth Like a Girl." Gender and Society, Michigan, v. 1, p. 54-72, fev. 2003.

MENEZES, Rachel A. Em busca da boa morte: antropologia dos cuidados paliativos. Rio de Janeiro: Garamound, 2004.

MONDADA, Lorenza. "Therapy Interactions. Specific Genre or 'Blow up' Version of Ordinary Conersational Practices?" Pragmatics, v. 8, n. 2, p. 1555-1565, 1998.

OSTERMANN, Ana Cristina. "Communities of Practice at Work: Gender, Facework and the Power of Habitus at an AllFemale Police Station and a Feminist Crisis Intervention Center in Brazil." Discourse \& Society, v. 14, n. 4, p. 473505, 2003.

. Comunidades de prática: gênero, trabalho e face. In: HEBERLE, Viviane M.; OSTERMANN, Ana Cristina; FIGUEIREDO, Débora de C. (Org.). Linguagem e gênero no trabalho, na mídia e em outros contextos. Florianópolis: UFSC, 2006. p. 15-47.

POMERANTZ, Anita. "Telling my Side: 'Limited Access' as a 'Fishing' Device." Sociological Inquiry, p. 186-198, 1980.

POMERANTZ, Anita; FEHR, B. J. "Conversation Analysis: An Approach to the Study of Social Action as Sense Making Practices." In: VAN DIJK, Teun A. (Ed.). Discourse as Social Interaction: Discourse Studies 2. A Multidisciplinary Introduction. London: Sage, 1997. p. 64-91.

POTTER, Jonathan. Representing Reality: Discourse, Rhetoric and Social Construction. London: Sage, 1996.

. "Discourse Analysis as a Way of Analysing Naturally Occurring Data." In: SILVERMAN, David (Ed.). Qualitative Research: Theory, Method and Practice. 2. ed. London: Sage, 2004. p. 200-221.

ROHDEN, Fabíola. Uma ciência da diferença: sexo e gênero na medicina da mulher. Rio de Janeiro: Fiocruz, 2001.

"A construção da diferença sexual na medicina". Cadernos de Saúde Pública, v. 19, n. 2, p. 201-212, 2003.

RUUSUVUORI, Johanna. "Comparing Homeopathic and General Practice Consultations: The Case of Problem Representation." Communication \& Medicine 2, Special Issue 'Professional Theories and Institutional Interaction', p. 123-36, 2005.

SACKS, Harvey. Lectures on Conversation. Oxford: Blackwell Publishers, 1992.

SACKS, Harvey; SCHEGLOFF, Emanuel; JEFFERSON, Gail. "A Simplest Systematics for the Organization of Turn-Taking for Conversation." Language, v. 50, n. 4, p. 696-735, 1974. 
SCHEPER-HUGHES, Nancy. "Nervoso: Medicine, Sickness, and Human Needs." In: Death Without Weeping: The Violence of Everyday Life in Brazil. Berkeley: University of California Press, 1992.

SCHIEBINGER, Londa. "Skeletons in the Closet: The Illustrations of the Female Skeleton in Eighteen-Century Anatomy." In: GALLAGNER, Catherine; LAQUEUR, Thomas. The Making of the Modern Body. London: University of California Press, 1987.

SCHNACK, Cristiane; PISONI, Thaís D.; OSTERMANN, Ana Cristina. "Transcrição de fala: do evento real à representação escrita". Entrelinhas, v. 2, n. 2, 2005.

SELL, Mariléia. Identidades de gênero negociadas na falaem-interação na negociação da esterilização. $104 \mathrm{f}$. Dissertação (Mestrado em Lingüística Aplicada), Universidade do Vale do Rio dos Sinos, 2007.

SILVERMAN, David. Social Science and Conversation Analysis. New York: Oxford University Press, 1998.

SPEER, Susan. Gender Talk: Feminism, Discourse and Conversation Analysis. New York: Rotledge, 2005.

WEATHERALL, Ann. "Towards Understanding Gender and Talkin-Interaction." London: Discourse and Society, v. 13, n. 6, p. 767-781, 2002.

WENGER, Etiene. Comunities of Practice: Learning, Meaning and Identity. New York: Cambridge University Press, 1998.

WEST, Candace; ZIMMERMAN, Don H. "Small Insults: A Study of Interruptions in Cross-Sex Conversations between Unacquainted Persons." Language, Gender and Society, Massachusetts, v. 30, p. 102-1115, 1983.

[Recebido em $1^{\circ}$ de julho de 2010 e aceito para publicação em 9 de maio de 2011]

\begin{abstract}
"My Mom got Bitter": Expectations of Maternity Performances Negotiated through Talk-in-Interaction

Abstract: The post-structuralist conception of identity, from an ethnomethodological perspective, brought deep changes to the way gender and language relations are established. Gender is thus taken as a social construction, which needs to be (re)negotiated in every and each new interaction and, since it does not exist outside discourse, it does not have a fixed and stable status. To understand how gender identities are interactionally negotiated, and here considering specifically the aspects related to maternity, I present the importance of Conversation Analysis, through the qualitative analysis of naturalistic interactions between a psychologist and candidates for vasectomy and tubal ligation, which occurred at a public health center in the south of Brazil. What is shown, through the analysis of three excerpts of interaction, is that small perturbations in the performances of maternity trouble the notion of a stable maternity, which gives us a practical idea of the concept of agency.
\end{abstract}

Key Words: Talk-in-Interaction; Language; Identities; Gender; Maternity. 


\section{APÊNDICE A - CONVENÇÕES DE TRANSCRIÇÃO}

\begin{tabular}{|c|c|}
\hline [texto] & Falas sobrepostas \\
\hline$=$ & Fala colada \\
\hline$(1.8)$ & Pausa \\
\hline (.) & Micropausa \\
\hline , & Entonação contínua \\
\hline . & Entonação ponto final \\
\hline$?$ & Entonação de pergunta \\
\hline- & Interrupção abrupta da fala \\
\hline : & Alongamento de som \\
\hline$>$ texto $<$ & Fala mais rápida \\
\hline$<$ texto $>$ & Fala mais lenta \\
\hline${ }^{\circ}$ texto ${ }^{\circ}$ & Fala com volume mais baixo \\
\hline TEXTO & Fala com volume mais alto \\
\hline Texto & Sílaba, palavra ou som acentuado \\
\hline (texto) & Dúvidas \\
\hline$X X X X$ & Texto inaudível \\
\hline ((texto)) & Comentários da transcritora \\
\hline @@@ & Risada \\
\hline$\downarrow$ & Entonação descendente \\
\hline$\uparrow$ & Entonação ascendente \\
\hline hhh & Expiração audível \\
\hline. $\mathrm{hhh}$ & Inspiração audível \\
\hline
\end{tabular}

Fonte: SCHNACK, PISONI e OSTERMANN, 2005. 